\title{
Raízes do Brasil: do silêncio à permanência
}

\author{
Alceste Pinheiro \\ UFF
}

Outubro de 1936. Uma gráfica de São Paulo, contratada por uma das mais importantes editoras brasileiras, a José Olympio, do Rio de Janeiro, encerra a impressão de um livro de 176 páginas. A expectativa é de que será uma obra importante, que marcará uma fase da história brasileira. Tanto que é escolhida por um escritor conceituado, de sucesso e respeitado, Gilberto Freyre, para abrir a coleção Documentos Brasileiros, que o já consagrado autor de Casa grande\&senzala dirigia. Seu autor, um jovem, mas já experiente, jornalista muito conhecido, que fora correspondente de O.Jornal na Alemanha: Sérgio Buarque de Holanda. Portanto, o livro estava destinado ao sucesso.

Em uma época em que se buscava explicações para o Brasil, em que três anos antes os intelectuais brasileiros receberam com aplausos Casa grande\&senzala e Evolução política brasileira, este de Caio Prado Júnior, Raizes do Brasil vinha somar-se a um conjunto de obras que busca fixar, interpretar ou esclarecer "aspectos significativos da nossa formação ou da nossa atualidade", como indicava Gilberto Freyre na apresentação da obra, na primeira edição do livro, em texto escrito em Recife e datado de julho de 1936'. Principalmente por que o caminho que tomava era evidentemente outro, conforme irá assinalar Antônio Cândido cinqüenta anos depois, em 1986:

Raizes do Brasil, caso diferente e curioso, exprime um veio pouco conhecido, pouco localizado e pouco aproveitado de nosso pensamento politico-social. em cuja massa predominantemente liberal e conservadora ele aparece de maneira recessiva, extremada ou excepcional. Falo 
do que se poderia o radicalismo potencial das classes médias, que no caso de Sérgio adquire timbre diferenciador, ao voltar-se decididamente para o povo. Talvez tenha sido ele o primeiro pensador que abandonou a posição "ilustrada", segundo a qual cabe a esclarecidos intelectuais, politicos, governantes, administrar os interesses e orientar a ação do povo (...). Sérgio deixou claro que só o próprio povo, tomando a iniciativa, poderia cuidar do seu destino. Isto faz dele um coerente radical democrático, autor da contribuição que deve ser explorada e desenvolvida no sentido de uma política popular, adequada às condições do Brasil, seguindo princípio ideológicos definidos ${ }^{2}$.

Entretanto, toda a expectativa viu-se frustrada. A repercussão da obra não se aproximou em nada da que teve, por exemplo, Casa Grande\&Senzala, recebida como se há muito esperada ${ }^{3}$. O livro vendeu pouco e, o pior, os críticos dos principais jornais da época, a exceção de um, o ignoraram ${ }^{4}$.

Por que esse silêncio que reuniu dois jornais paulistas - o Estado de São Paulo e o Correio Paulistano - e um carioca - O Jornal -? Silêncio, aliás, nunca publicamente comentado por Sérgio Buarque de Holanda. Por que apenas o Jornal do Brasil, do Rio de Janeiro, mencionou o lançamento de Raizes do Brasil? Por que se calaram críticos importantes como Plínio Barreto, Nelson Werneck Sodré, Agripino Griecco e Otávio Tarquínio de Sousa? Por que só Múcio Carneiro Leão falou do livro?

Três hipóteses são plausíveis:

1. Sérgio Buarque de Holanda exercia o ofício de crítico literário desde a década de 1910; tendo iniciado a carreira no Correio Paulistano ${ }^{5}$. Participou do Movimento Modernista de 1922 e escreveu para as revistas Klaxon, da qual foi representante na Capital Federal, e Estética, que fundara no Rio de Janeiro com Prudente de Morais Neto. Sem dúvida o exercício crítico por si mesmo já estabeleceria inimizades e incompreensões - sentimentos que poderiam ser aguçados em relação a Sérgio Buarque de Holanda, herdeiro da crítica ferina e rigorosa dos modernistas.

2. Do Modernismo, Sérgio Buarque de Holanda herdara também o temperamento descontraído e debochado. Jovem ainda nos anos 20, o autor de Raizes do Brasil freqüentava rodas boêmias e tinha amigos entre músicos populares. Isso pode ter desagradado aos colegas e a um 
ambiente que prezava a aparência.

3. Por fim. em Raizes do Brasil, Sérgio Buarque de Holanda critica a ação política de liberais, integralistas e comunistas, que ocupavam postos chaves na imprensa de então. Ao lado disso, ele não deixa transparecer em nenhum momento de que lado estaria em uma época $\mathrm{em}$ que se prezava as posições definidas. Era um escorregadio. Isso não passou despercebido ao único crítico que comentou a obra, Múcio Leão, para quem "o autor de Raizes do Brasil (...), em tal campo, me parece cheio de contradições".

\section{O cenário}

Raízes do Brasil é o depositário do caudaloso rio dos anos 20 no Brasil. Década de lutas internas radicais, de fundação do Partido Comunista, que acaba por reunir diversas correntes da luta operária e neutralizar o movimento anarquista. Década do estado de sítio permanente do governo Bernardes, dos Dezoito do Forte, de rebeliões em São Paulo e Rio Grande do Sul. Década revolucionária que se encerra com o Movimento de 1930. Década em que o negro consegue lugar nas fábricas. Década não somente de luta, mas também de reflexão sobre o Brasil. Anos modernistas.

Sérgio Buarque de Holanda é certamente herdeiro de um tradição reflexiva: a tradição de pensar o Brasil. Tradição que começa ainda na Colônia; que prossegue com os românticos do século passado que se deram a missão de construir uma literatura nacional autônoma: que encontra novas bases na Geração de 70 de Sílvio Romero, Manuel Bonfim e Euclides da Cunha. Tradição fortalecida com Alberto Torres e Oliveira Vianna, este patriarca de uma linhagem de explicadores do Brasil que tem em Gilberto Freyre a sua continuidade. embora a partir de outros fundamentos teóricos?

As estratégias de um novo ordenamento político-cultural estão postas. Ao final do século XIX, o objetivo é "civilizar-se", aproximar-se da Europa, a fim de competir no mercado internacional. Ao contrário. nos anos de 1920 e 1930, grupos de jovens intelectuais buscam ajustar as contas com o passado e adequar as idéias modernas ao Brasil, institucionalizá-las.

É preciso encontrar uma "identidade nacional", inventá-la. Entretanto. tal operação - que compreendia uma dimensão sem dúvida autoritária - não deveria impedir a importação das vanguardas européias e nor- 
te-americanas. Somos uma nação distinta do Velho Mundo, mas uma nação ocidental.

Militante modernista, intelectual atuante, Sérgio Buarque de Holanda, sem dúvida alguma, integrava o grupo dos que se propunham a inventar o Brasil moderno. Os modernistas de 22 já tinham dado uma guinada no movimento, entrando na fase de elaboração de uma cultura nacional. Se até 1925 haviam bombardeado tudo o que consideravam passadismo, em busca do que qualificavam de "atualização", a fase agora é de reencontrar o Brasil ${ }^{8}$.

Sérgio Buarque de Holanda fora o principal divulgador das idéias dos modernistas no Rio de Janeiro, para onde se transferira em $1921^{9}$. Era quase um representante oficial do movimento na Capital da República $^{10}$. Fora editor da revista Estética, junto com Prudente de Morais Neto, o Pedro Dantas. A publicação tinha Graça Aranha por diretor. Uma associação dificil com autor de Canaã, discípulo de Tobias Barreto na Faculdade de Direto de Recife"

Apesar disso, Estética teve um papel de ponta na renovação intelectual brasileira dos anos 20. Alguns dos mais importantes escritores nacionais puderam se tornar conhecidos, entre eles Aníbal Machado, Carlos Drummond de Andrade, Antônio de Alcântara Machádo, Rodrigo de Melo Franco.

Portanto, nos anos 20, apesar da pouca idade, já era um intelectual respeitado, considerado um homem de letras, o que seria um arcaico nos dias que correm, tempos de cultura setorizada e especializada. Em torno dele se reunia um grupo de jovens modernistas, os jovens turcos, que incluía também Afonso Arinos de Mello Franco $^{12}$ e Villa-Lobos.

Era um grupo de mediadores culturais, de longa tradição no Rio de Janeiro. Intelectuais brancos, eruditos, ligados à tradição ocidental, assumem o papel de buscar entre os subalternos as "fontes da genuína" cultura nacional. Transitam entre ricos e pobres, brancos e negros, e portam informações que serão aproveitadas pelos dois grupos. Promovem a interação e os contatos entre os diferentes. Acionam o cadinho que vai dissolver as distinções e fazer surgir a soma de mundos diferentes $^{13}$. É um agente modernizador ${ }^{14}$.

Sérgio Buarque de Holanda foi um mediador cultural dos anos 20 na cidade do Rio de Janeiro. Como o foram Laurindo Rabelo, músico e médico militar, o escritor Mello de Morais Filho, Alexandre Trovador, Catulo da Paixão Cearense. Esses mediadores elegem espaços privilegi- 
ados de mediação. onde as diferenças se tocam e iniciam o processo de fusão e de troca.

Espaço de mediação cultural foram os salões de algumas famílias elegantes do Rio de Janeiro. Foi a Tipografia de Francisco de Paula Brito, frequientada em outras épocas por José de Alencar, Machado de Assis, que ali aprendeu o oficio de impressor, e Gonçalves Dias ${ }^{15}$. Muitos espaços de mediação foram destruidos no início do século com a Reforma de Pereira Passos, que, entre outros objetivos, buscou a segregação de ricos e pobres. em um primeiro processo organizado de partir a cidade em duas, cujos efeitos são sentidos até hoje.

Foi nesse papel de mediador cultural que Sérgio Buarque de Holanda ciceroneou o poeta francês Blaise Cendrars, em sua visita ao Rio, junto com Prudente, Ronald de Carvalho, Américo Facó e Afonso Arinos. Foi nesse papel de mediador cultural que ele, de novo com Prudente de Morais Neto, promoveu em 1926 o encontro de Gilberto Freyre, que chegara do Recife em visita ao Rio de Janeiro, com um grupo de compositores populares formado por Patricio Teixeira. Donga e Pixinguinha. Desse encontro, em um bar da rua do Catete, em frente à antiga Faculdade de Direito, há poucos metros do então palácio do governo, participou dois compositores eruditos Heitor Villa-Lobos e Luciano Gallet ${ }^{16}$.

Três anos depois desse encontro, em 1929, Sérgio Buarque de Holanda passa um periodo na Alemanha. Estuda e trabalha como correspondente de Ojornal, a convite de Assis Chateaubriand, que conhecera na Revista do Brasil. É nesse período em que vai começar a escrever Raízes do Brasil, inicialmente um livro sobre as raizes da América. Dois capítulos são produzidos em Berlim, sob o influxo da influência de Weber ${ }^{17}$.

Sérgio era autor de vários textos de crítica literária publicados na imprensa. mas não produzira ainda nenhum livro. Seus amigos de então esperavam uma obra importante escrita por ele a qualquer momento. Principalmente por ser ele então "o homem que mais ama os livros. que mais religiosamente os lê (...) e o mais fecundo descobridor de títulos de livros que o Brasil tem possuído" $"$.

Essa virtude é enfatizada por Gilberto Freyre no texto em que abre a série Documentos Brasileiros, publicado na primeira edição de Raízes do Brasil:

O escritor paulista é uma daquelas inteligéncias brasileiras em que 
melhor se exprimem não só o desejo como capacidade de analisar, o gosto de interpretar, a alegria intelectual de esclarecer. Quando apareceu, há dez ou doze anos (...) foi logo revelando as qualidades e o gosto, que agora se afirmam vitoriosamente ${ }^{19}$.

Entretanto, pelo que o já acadêmico Múcio Carneiro Leão ${ }^{20}$ dizia dele na época parecia que Sérgio Buarque de Holanda não primava pela seriedade. Pelo menos era assim que os seus contemporâneos o viam, conforme deixa transparecer no mesmo texto.

São muitas as facetas do seu espírito, muitas as suas contradições, muitas as surpresas que todos os dias ele nos traz. Sua faculdade para as coisas espantosas é tamanha que ninguém se surpreenderia com qualquer atitude que ele assumisse. Não nos causaria espanto, por exemplo, vê-lo amanhã transformado num cacique de tribo indigena, vê-lo amanhã realizando proezas de pirata em mares distantes, vê-lo amanhã coroado 9como Rei da Mandchuria ou mesmo da Inglaterra. Quem de nós não teve ainda a certeza de que o senhor Sérgio Buarque de Holanda iria acabar escrevendo uma epopéia obscura e tremenda como Ulisses de Joyce, ou atuando na tela cinematográfica com a graça de um dos irmãos Marx, ou mesmo - eximio tocador de piano que ele é - executando maxixes e fox-trotes em algum café cantante da Lapa. Para nós, Sérgio Buarque de Holanda é, como Voltaire dizia do profeta Habacuc, capaz de $t u d o^{21}$.

O curioso é que logo a seguir Múcio Leão tenta suavizar o discurso, retornando ao tom em que reconhecia a capacidade e as virtudes intelectuais de Sérgio Buarque de Holanda, como que querendo dizer que, por trás daquela personalidade curiosa, se escondia um verdadeiro intelectual, aquele que amava os livros:

Um homem tranqüilo, o mais natural, o mais encantador dos homens. Ele constrói sua vida com harmonia, modéstia e doçura (..). E todo aquele seu tumulto, todo aquele seu imenso tumulto de boemia e originalidade, é puramente um fato da imaginação $o^{22}$

O texto é do único crítico que anuncia o lançamento da obra. Jornalista pernambucano que convivia nas rodas da boemia intelectual com 
Sérgio Buarque de Holanda e que muitas vezes recebia com ele, em sua casa, músicos populares. Múcio, que se elegera no ano anterior para a Academia Brasileira de Letras, precisou construir um discurso em que não deslegitimava a capacidade intelectual de Sérgio Buarque de Holanda, mas the reconhecia o caráter boêmio e tumuituoso, "capaz de tudo", o que devia ser voz corrente no ambiente intelectual da Capital Federal - ambiente limitado, em que todos conheciam todos e no qual devia subsistir muita rivalidade, inveja e desavença pessoal. Sobretudo em relação a um crítico modernista 23 .

Como crítico - observa Alexandre Eulálio -, Sérgio "persegue uma seriedade de reflexão muito dele. Isto sem abandonar as componentes de humorismo ou de sarcasmo, manejados de modo sutil" "24. Alguns dos principais escritores brasileiros sofrem criticas francas de Sérgio Buarque de Holanda, até mesmo os amigos, como Ronald de Carvalho. Comportamento semelhante, ele terá em outras publicações - Terra roxa e outras terras, Revista do Brazil e O jornal. Estará nisso a causa do silêncio sobre Raíes do Brasil em seu lançamento? Silêncio que se prolongará até 1948, quando então a obra alcança a sua segunda edição.

\section{A obra}

Esse silêncio não faz jus à importância da obra ${ }^{25}$, como assinala Antônio Cândido no prefácio que passou a acompanhar o livro a partir da edição de 1963, a quarta. Cândido situa Raizes do Brasil no mesmo patamar de Casa grande\&senzala, de Freyre, e Formação do Brasil Contemporâneo, de Caio Prado Júnior - livros-chaves para uma geração que aprendeu "a refletir e a se interessar pelo Brasil" em meio "ao sopro de radicalismo intelectual e de análise social que eclodiu depois da Revolução de 1930 e não foi, apesar de tudo, abafado pelo Estado Novo"26. O livro foi um instrumento de compreensão para os jovens em um momento de descrença no Liberalismo e de avanço das posições à direita, como Integralismo, e à esquerda, com o Socialismo e o Comunismo.

Cândido chama a atenção para o respaldo teórico de Raizes do Brasil, que "prendia-se à nova história social dos franceses, à sociologia da cultura dos alemães, a certos elementos da teoria sociológica e etnológica" 27 inéditos no Brasil. Porém o que Cândido mais enfatiza é a metodologia adotada por Sérgio Buarque de Holanda - "uma admirável metodologia dos contrários" 28 . Em verdade, não é uma metodologia nova. Esse método de pares antitéticos estava em uso na Alemanha. $\mathrm{O}$ 
próprio Antônio Cândido recorda que a reflexão sobre a realidade social, desde Sarmiento, foi marcada pelo senso dos contrastes e dos contrários. Não é assim toda a construção de Os sertões?

De fato, os contrários marcam Raizes do Brasil. O primeiro deles está na implantação da cultura européia em um território "dotado de condições naturais, se não adversas, largamente estranhas à sua tradição milenar", o que nos faz "ainda hoje uns desterrados em nossa terra" 29. Dessa condição decorre a falta de coesão social, problema tão apontado nos anos 20 e 30. Sérgio Buarque de Holanda salienta que essa cisão não é fenômeno moderno, o que joga por terra o argumento de que a volta a uma "certa tradição é a única defesa possível contra a nossa desordem" ${ }^{30}$. O escritor indica a sua primeira opção política: a de virar as costas para o passado. Seu recado tem um destino certo:

Os mandamentos e as ordenações que elaboram esses eruditos são, em verdade, criações engenhosas do espírito, destacadas do mundo e contrárias a ele. Nossa anarquia, nossa incapacidade de organização sólida, não representam, a seu ver, mais do que uma ausência da única ordem que lhes parece necessária e eficaz. Se a considerarmos bem, a hierarquia que exaltam é que precisa de tal anarquia para se justificar e ganhar prestígio" ${ }^{\prime \prime 1}$.

Sérgio Buarque de Holanda está então convencido de que o princípio de hierarquia pregado naquele momento não tinha base na tradição que os seus arautos apregoavam. Na visão do escritor, a nobreza lusitana "nunca chegou a ser rigorosa impermeável" ${ }^{32}$ e que o mérito pessoal, fundado na fortuna material, "os altos feitos e as altas virtudes" ravam os privilégios hereditários, o que torna Portugal e Espanha "legítimas pioneiras da mentalidade moderna" ${ }^{134}$.

A base dessa visão de mundo estava no livre-arbítrio, contrário aos princípios da predestinação, que, a grosso modo, explica os êxitos e os fracassos dos individuos por uma força que o transcende e contra a qual não tem muito o que fazer. Contra essa visão de mundo insurgiram-se os jesuitas, que criaram uma forte repulsa contra qualquer teoria que negasse o livre-arbítrio e que não reconhecesse plenamente o mérito e a responsabilidades pessoais ${ }^{35}$.

Para Sérgio Buarque de Holanda, as doutrinas do livre arbítrio e da responsabilidade individual impediram em Portugal e Espanha o espíri- 
to de organização espontânea, que caracteriza os povos protestantes. Daí porque nas nações ibéricas o Estado teve sempre muita importância, com o governo representando o princípio unificador. Vai aí, sem dúvida, uma forte critica aos liberais dos anos 30 (e certamente também aos de hoje).

Como o Estado é o principio unificador e como faltam coesão social e capacidade organizativa, é necessário estabelecer principios de obediência, no que os jesuítas foram mestres. E é olhando o passado com os olhos voltados para o presente e para o futuro que Sérgio Buarque de Holanda ensina:

Desaparecida a possibilidade desse freio, é em vão que temos procurado importar dos sistemas de outros povos modernos, ou criar por conta própria, um sucedâneo adequado, capaz de superar os efeitos de nosso natural inquieto e desordenado ${ }^{36}$.

Outro contraste é trabalho e aventura, que dá título ao segundo capitulo..Em resumo, Sérgio Buarque de Holanda considera que o Brasil foi colonizado por aventureiros, o que ele considera positivo porque a produção de cana seria impossivel sem esse espírito que busca experiência, acomoda-se ao provisório, prefere descobrir a consolidar, tem capacidade de adaptação à alimentação, aos hábitos da terra e às condições de moradia ${ }^{37}$.

Em uma época em que os focos do olhar da elite nacional ainda estavam voltados para a Europa e os Estados Unidos, Sérgio Buarque de Holanda encontra uma forma de atacar um dos mitos mais discutidos na época: a de que a colonização holandesa teria sido melhor para o país. Os holandeses fracassaram no empreendimento pernambucano. Foram inaptos para fundar a propriedade da terra. A opulencia do Recife, a opulência urbana, contrastava com a pobreza rural. $\$$.

Sérgio concorda que a colonização portuguesa foi levada a cabo com desleixo e certo abandono, o que não vê com olhar negativo. Contesta a idéia de que a empreitada tenha resultado em fracasso". A ética do aventureiro favoreceu a mobilidade social ${ }^{40}$ e permitiu a ausência completa. ou praticamente completa, de qualquer orguiho de raça. Ao menos o orgulho obstinado que caracteriza os povos do norte ${ }^{41}$

Aí Sérgio Buarque de Holanda aborda uma questão importante e recorrente entre muitos intelectuais brasileiros daquela geração, a questão 
racial. O português não tinha o obstinado orgulho de raça que caracteriza os povos do Norte, como os holandeses, porque, ao tempo do Descobrimento, já eram mestiços ${ }^{42}$. Dai é possível concluir, como Gilberto Freyre e mais recentemente com Darcy Ribeiro, que ser mestiço é bom.

Sérgio lembra que as autoridades coloniais estimulavam o casamento mistos entre indígenas, conforme um alvará de 1755. E faz uma afirmação capaz ainda hoje de provocar protestos em alguns setores ${ }^{43}$, mas que são modernas. Basta observar as recentes pesquisas da historiografia contemporânea sobre a escravidão, no Brasil e nos Estados Unidos.

O escravo das plantações e das minas não era um simples manancial de energia, um carvão humano à espera de que a época industrial o substituisse pelo combustivel. Com freqüencia em suas relações com os donos oscilavam de situação de dependente para a de protegido, e até de solidário e afim. Sua influência penetrava sinuosamente o recesso doméstico, agindo como dissolvente de qualquer idéia de separação de castas ou raças, de qualquer disciplina fundada em tal separação. Essa era a regra geral: não impedia que tenham existido casos particulares de esforços tendentes a coibir a influencia excessiva do homem de cor na vida da colônia ${ }^{44}$.

E mais: teria fracassado qualquer tentativa portuguesa de the impor um freio. Sobressai aí a influência de Gilberto Freyre em Raizes do Brasil.

À influência do negro, não apenas como negros, mais ainda, e sobretudo, como escravos, essa população não tinha como oferecer obstáculos sérios. Uma suavidade dengosa e açucarada invade, desde cedo, todas as esferas da vida colonial. Nos próprios dominios da arte e literatura ela encontra meio de exprimir-se, a partir principalmente dos Setecentos e do Rococó. O gosto exótico, da sensualidade brejeira, do chichisbeismos, dos caprichos sentimentais parecem fornecer-lhes um providencial terreno de eleição, e permitem que, atravessando oceano, vá exibir-se em Lisboa, com os lundus e modinhas do mulato Caldas Barbosa ${ }^{45}$.

Ver o mestiço como um valor era uma operação empreendida por alguns intelectuais dos anos 20 e 30 . O Brasil poderia sair do atraso, tri- 
Ihar o caminho reservado às grandes nações, independente de ser um país de mestiços - razão do pessimismo da maioria dos intelectuais das gerações anteriores. Era mão de obra valiosa para o capitalismo internacional que se desejava implantar no Brasil ${ }^{46}$.

A valorização do mestiço soma-se uma politica cultural homogeneizadora, centralizadora e unificadora, antitese da politica heterogeneizadora e descentralizadora da República Velha, federalista essencialmente. Naquela hora, a unificação do país, sua homogeneização, era a escolha da Revolução de 30 e dos intelectuais daquela década, entre eles Sérgio Buarque de Holanda e Gilberto Freyre $^{47}$. E o mestiço - mais que todos, o mulato - era sinal da homegeneização pretendida, a dissolução das diferenças em um todo único ${ }^{48}$.

Entretanto, ao contrário de Freyre, Sérgio Buarque de Holanda procura outras bases, o que o afasta do escritor pernambucano, como já observara Antônio Cândido:

Um momento em que os intérpretes do nosso passado ainda se preocupavam sobretudo com os aspectos de natureza biológica, manifestando, mesmo sob a aparência do contrário, a fascinação pela 'raça', herdada dos evolucionistas, Sérgio Buarque de Holanda puxou a sua análise para o lado da psicologia e da história social, com um senso agudo das estruturas, num tempo ainda banhado de indisfarçável saudosismo patriarcalista, sugeria que, do ponto de vista metodológico, o conhecimento do passado deve estar vinculado aos problemas do presente. E do ponto de vista politico. que, sendo o nosso passado um obstáculo, a liquidação das 'raizes' era um imperativo do desenvolvimento históri$\mathrm{co}^{49}$.

Outro contrate dessa dialética dos contrários é a relação meio urbano-meio rural, explicitada no terceiro capítulo. Mesmo o Brasil contemporâneo de Sérgio Buarque de Holanda sofria o forte influxo da mentalidade rural. Ainda viviam no campo cerca de 70 por cento da população nacional. Portanto, é explicável que essa questão incomodasse os intelectuais da época, sobretudo porque a Revolução de 30 se pretendia neutralizadora da oligarquia rural paulista.

A questão. entretanto. não é meramente de quantidade. A sociedade brasileira. embora sem ser rigorosamente uma sociedade agrícola. é de 
raizes rurais, sendo as cidades dependentes das fazendas. Portanto a questão é de mentalidade. Os fazendeiros escravocratas monopolizaram toda a vida nacional, até as idéias liberais, daí o malogro de um Mauá ${ }^{50}$.

O proprietário de terra, que "nos domínios rurais (...) não sofria réplica"5l, transplantará essa autoridade absoluta para a administração pública. São seus herdeiros que exercerão o trabalho mental, que no Brasil "não significa forçosamente (...) amor ao pensamento especulativo (...) mas amor à frase sonora, ao verbo espontâneo e abundante, à erudição ostentosa, à expressão rara" 52 . Um trabalho mental meramente expressionista, rococó, barroco mesmo, "ornamento e prenda, e não instrumento de conhecimento e de ação"

Outra oposição aparece no capítulo seguinte, $O$ semeador $e o$ ladrilheiro. O contraste, nesse caso, se dá, entre a colonização portuguesa e a espanhola. Por causa do caráter meramente de exploração comercial - afirma Sérgio Buarque de Holanda -, a estratégia de Portugal na América previa a ocupação apenas do litoral, com o abandono do interior. Ação dos bandeirantes, por exemplo, fazia-se contra a vontade e os interesses da metrópole. Ao contrário, a estratégia colonizadora espanhola previa a criação de grandes núcleos de povoação estáveis e bem ordenados no interior da América ${ }^{54}$.

O Capítulo $\mathrm{V}$ foi o que provocou a maior polêmica nos anos seguintes. O conceito de homem cordial ali expresso foi objeto de controvérsias - a primeira com o poeta Cassiano Ricardo - e obrigou Sérgio Buarque a tentar explicá-lo várias vezes. O termo - conforme o próprio escritor o confirma nas edições seguintes - nasce com Ribeiro Couto em carta a Afonso Reyes, e está longe de significar bondade, como o quer Ricardo ${ }^{55}$.

Já no final da vida, no ano em que a obra completaria 40 anos, Sérgio Buarque de Holanda teve ainda que explicar o sentido do conceito, "que poucos entenderam":

Não é no sentido de "cordiais saudações", como Cassiano Ricardo o fez. A cordialidade com que caracterizei o brasileiro pode ocorrer mesmo em situações de confronto, fatos comuns em nossa história (...). É inegável (...) que a Independência, a Proclamação da República e mesmo as revoluções de 1930 e $196+$ se fizeram sem derramamento de sangue. Portanto, a cordialidade continua valendo para nossa histó$r i a^{56}$. 
O sentido do conceito foi assim expresso por um dos admiradores de Raizes do Brasil:

O "homem cordial" não pressupõe bondade, mas somente o predominio dos comportamentos de aparência afetiva, inclusive suas manifestações externas, não necessariamente sinceras nem profundas, que se opõem aos ritualismos da polidez. O "homem cordial" $\dot{e}$ visceralmente inadequado às relações impessoais que decorrem da posição e da função do indivíduo, e não de sua marca pessoal e familiar, das afinidades nascidas na intimidade dos grupos primários ${ }^{57}$.

No entender de Sérgio Buarque de Holanda, o brasileiro não acha agradável a relação impessoal, que é uma característica do Estado, preferindo a pessoal e afetiva, a relação do coração. O processo de urbanização neutraliza de alguma forma essas relações de impessoalidade, o que vai "acarretar um desequilíbrio social, cujos efeitos permanecem vivos hoje"ss. Para dar um fundamento sociológico ao conceito de homem cordial, Sérgio busca Max Weber, que tomara contato em sua estada na Europa. Antônio Cândido acha que pela primeira vez no Brasil, os conceitos weberianos de "patrimonialismo" e "burocracia" são empregados no Brasil ${ }^{59}$. Diz Buarque de Holanda:

Não era fácil aos detentores das posições públicas de responsabilidade, formados por tal ambiente. comprenderem a distinção fundamental entre os dominios do privado e do público. Assim, eles se caracterizam justamente pelo que separa o funcionário "patrimonial" do puro burocrata, conforme a definição de Max Weber. Para o funcionário "patrimonial". a própria gestão politica apresenta-se como assunto de seu interesse particular: as funções, os empregos e os beneficios que deles aufere, relacionam-se a direiros pessoais do funcionário e não a interesses objetivos, como sucede no verdadeiro Estado burocrático, em que prevalecem a especialização das funções e o esforço para se assegurarem garantias juridicas aos cidadãos ${ }^{60}$.

O último capítulo de Raizes do Brasil - Nossa revolução - é pleno de recados para integralistas. comunistas e liberais. Em década ainda marcada pelo ideal de revoluçào. Sérgio Buarque de Holanda abre mão 
de qualquer radicalismo. Para ele, a revolução brasileira é um processo lento, jamais abrupto.

A grande revolução brasileira não é um fato que se registrasse em um distante preciso; $\dot{e}$ antes um processo demorado e que vem durando pelo. menos há três quartos de século. Seus pontos culminantes associam-se como acidentes diversos de um mesmo sistema orográfico. Se em capítulo anterior se tentou fixar a data de 1888 como o momento talvez mais decisivo de todo o nosso desenvolvimento nacional, é que a partir dessa data tinham cessado de funcionar alguns dos freios tradicionais contra o advento de um novo estado de coisas, que só então se faz inevitável. Apenas nesse sentido é que a Abolição representa, em realidade. O marco inicial mais visivel entre as duas épocas ${ }^{61}$.

Após a Abolição - teoriza Sérgio Buarque de Holanda -, o centro de poder se desloca dos domínios rurais para os centros urbanos. Mesmo no campo, processou-se uma mudança na "silhueta antiga do senhor de engenho"62. O cafeicultor é mais despreendido da terra, da tradição e da rotina rural. Atua na cidade, transformando a fazenda em mero negócio, não mais em local de residência ou recreio.

A terra de lavoura deixa então de ser o seu pequeno mundo para se tornar unicamente seu meio de vida, sua fonte de renda e de riqueza. A fazenda resiste com menos energia à influência urbana, e muitos lavradores passam a residir permanentemente nas cidades (...) o dominio, agrário deixa, aos poucos, de ser uma baronia, para se aproximar, em muitos dos seus aspectos, de um centro de exploração industrial ${ }^{63}$.

Entretanto, a mentalidade rural permanece. Por isso, o nosso liberalismo é um liberalismo ornamental que pretende curar os males nacionais com leis - e leis importadas - e "a pura e simples substituição dos detentores do poder público" ${ }^{4}$. Sérgio. Buarque propõe uma "dissolução lenta (...) das sobrevivências arcaicas" 65 .

O autor encerra o livro com críticas às correntes hegemônicas na luta política e ideológica de uma época de definições e engajamentos radicais. Além do Liberalismo, que em muitos momentos parece ser o alvo preferido, Sérgio não poupa o Integralismo e o Comunismo. Em uma etapa da vida nacional que a revolução é a palavra de ordem para a di- 
reita e a esquerda, ele denuncia o caráter meramente contra-reformista do Integralismo. A energia do fascismo e do nazismo "transformou-se, aqui, em pobres lamentações de intelectuais neurastênicos"

No caso do fascismo, a variedade brasileira ainda trouxe a agravante de poder passar por uma teoria meramente conservadora, empenhada no fortalecimento das instituições sociais, morais e religiosas de prestigio indiscutivel, e tendendo, assim, a tornar-se praticamente inofensiva aos poderosos, quando não apenas o seu instrumento ${ }^{67}$.

Sérgio Buarque de Holanda observa que, no Brasil, o Comunismo atrai "precisamente aqueles que parecem menos aptos a realizar os princípios da Terceira Internacional" e revestiu-se de um caráter que combina "antes com a 'mentalidade anarquista', do que com a disciplina rígida que Moscou reclama de seus partidários" $" 68$.

Sem dúvida, lida nos dias de hoje, a crítica parece em nada agressiva ou deslegitimadora. Pelo contrário, lido todo o capítulo o que Sérgio parece defender é uma liquidação do passado de forma a "propiciar a emergência das camadas oprimidas da população, únicas com capacidade para revitalizar a sociedade e dar um novo sentido à vida política"69. Como o escritor propunha, uma dissolução lenta, na qual a soma poderia resultar algo capaz de dar um novo sentido à vida política. O próprio método adotado por Sérgio Buarque de Holanda "impede qualquer dogmatismo e abre campo para a meditação do tipo dialético"70.

Entretanto, em uma época de radicalismos, seis anos depois da Revolução de 30, quatro anos após a Revolta Paulista, um ano além da insurgência da Aliança Nacional Libertadora, dois anos antes do Estado Novo e a três do putsch integralista, a proposta de Sérgio Buarque de Holanda evidentemente não soou com o tempo. Esse poderia ser mais um motivo pelo qual um critico de esquerda, com Nelson Werneck Sodré. um simpatizante do Integralismo. como Agripino Griecco, ou um liberal ligado aos cafeicultores paulistas, como Plínio Barreto, tenham silenciado diante de Raizes do Brasil.

\section{A critica que silencia}

Mesmo Múcio Carneiro Leão não se aprotunda muito na análise de Raizes do Brasil. Com um destaque pouco habitual em sua coluna semanal. o jornalista limita-se a apresentar ao público o autor do livro. fa- 
lar de suas virtudes e caráter, de suas experiências como jornalista e crítico, de sua viagem à Europa. Só critica mesmo o fato de Sérgio Buarque de Holanda parecer por demais indefinido politicamente ${ }^{71}$.

Múcio Leão, entretanto, refere-se ao livro. Os críticos do Correio Paulistano, de $O$ Estado de São Paulo e de $O$ Jornal não fazem qualquer referência à Raizes do Brasil, não registrando sequer a sua chegada às livrarias, o que era uma praxe, com foi possível observar ${ }^{72}$.

Jornal em que Sérgio Buarque de Holanda começou a sua carreira de jornalista e escritor, $O$ Correio Paulistano fora fundado em 1854 como um jornal conservador, com "intervalos liberais"73. Na década de 1870 assumiu posições republicanas e, a partir de 1887, por influxo de Antônio Prado, seu então diretor, tornou-se abolicionista. Durante muito tempo, foi o único jornal diário da capital paulista, junto com o Diário de São Paulo. Na época em tela, era órgão do Partido Republicano e manifestava evidente apoio às tropas franquistas da Guerra Civil Espanhola e dava muito destaque ao Nazismo, ao Fascismo e ao Integralismo.

$\mathrm{Na}$ época do lançamento de Raizes do Brasil, o Correio Paulistano mantinha uma seção semanal - Livros Novos - de crítica literária, no qual também anunciava novos lançamentos. Entre outubro de $1936 \mathrm{e}$ dezembro de 1937 a coluna era de responsabilidade de Nelson Werneck Sodré, então um jovem de 25 anos.

Entre outubro de 1936 e dezembro de 1937, Nelson Werneck Sodré analisou mais de 50 títulos, alguns dos quais da José Olympio, como Experiência, de Marinho Nobre de Mello, e Geografia Sentimental, de Plínio Salgado, o que afasta a possibilidade de algum problema com a editora carioca. Como os outros, ignorou Raizes do Brasil, preferindo dedicar longo artigo, por exemplo, à História secreta do Brasil, de Gustavo Barroso, ao qual condena com veemência.

Plínio Barreto era o responsável pela seção Livros Novos, publicada aos sábados em O Estado de São Paulo, na época ligado ao Partido Democrático. Plínio Barreto estava de alguma forma vinculado ao jornal desde adolescente, começando a carreira como revisor. Em 1902, já formado em direito, passa a repórter - função que deixou três anos depois porque foi advogar no interior paulista. Quando retorna, em 1909, passa a redigir a seção Crônica Forense, mas tarde intitulada Vida Forense.

Teve intensa carreira jornalística e empresarial: foi proprietário do Comércio de São Paulo, da Revista dos Tribunais (1912) e do Diário da Noite (1923). Em 1927, ano da morte de Júlio Mesquita, tornou-se o re- 
dator-chefe do Estadão ${ }^{74}$. Era ligado aos cafeicultores paulistas e teve papel destacado na Revolução Constitucionalista de $32^{75}$. Plínio Barreto ignora também Raizes do Brasil durante 1936 e 1837.

No Rio de Janeiro, o O.Jornal - sob o aspecto técnico o mais moderno entre os consultados - mantinha duas seções de crítica literária, ambas aos domingos no suplemento Quarta Seç̧ão. Uma - a Letras e Artes - era assinada pelo irônico Agripino Griecco (Rio de Janeiro, 1888-1973). Era considerado um crítico mordaz, agudo, erudito e impressionista. Gozava de grande prestigio entre os modernistas, o que não o impediu de se revelar um simpatizante do Integralismo em uma de suas colunas. Também emudece diante de Raizes do Brasil ${ }^{70}$.

A outra seção - Vida Literária - também saía aos domingos e era assinada por Otávio Tarquínio de Sousa ${ }^{77}$. Com relação a esse crítico há um componente especial: um de seus livros, a biografia de Bernardo Pereira de Vasconcelos, integrou a coleção Documentos Brasileiros, aberta com Raizes do Brasil. No texto em que apresenta a coleção, Gilberto Freyre o cita especificamente ${ }^{78}$.

E mais: Tarquínio de Sousa dividia com Freyre a coordenação da coleção, da qual só se afastaria a partir do décimo oitavo volume, em 1939, quando Afonso Arinos de Melo Franco assumiu a sua direção. É bom lembrar que Freyre vivia em Recife e, em uma época de comunicação dificil, seu poder na coleção devia ser bastante acentuado. E não se pode esquecer que Otávio Tarquinio de Sousa foi o primeiro presidente da Associação Brasileira dos Escritores, em 1934. Ele também permanece mudo em relação ao Raizes do Brasil.

\section{A crítica que fala}

Se Ruizes do Brasil passou "despercebido" pela critica dos anos 30 , foi objeto de análises contundentes a partir dos anos 60. A maior parte dessas críticas saiu de professores da Universidade de São Paulo, da qual Sérgio Buarque de Holanda foi catedrático de História da Civilização Brasileira a partir de $1956^{79}$. Provavelmente esse fato, somado às produções posteriores do escritor. à orientação politica para a esquerda e ao trato pessoal carregado de cortesia e cordialidade ${ }^{80}$. suavizou um pouco a critica de toda uma geração de intelectuais formados na USP.

Para este trabalho. selecionei a avaliação critica de três professores da Faculdade de Filosofia, Letras c Ciências Humanas da USP: Alfredo Bosi. de Literatura Brasileira. em Um ressemumho do presente. prefácio 
de Ideologia da Cultura Brasileira; Dante Moreira Leite, já falecido, professor de psicologia e autor do erudito e já clássico $O$ caráter nacional brasileiro: história de uma ideologia ${ }^{81}$; e Carlos Guilherme da Mota, autor do importante Ideologia da cultura brasileira e professor de história.

Comecemos pelo mais antigo: Dante Moreira Leite. O caráter nacional brasileiro foi a tese de doutoramento em psicologia apresentada à Faculdade de Filosofia, Letras e Ciências Humanas em 1954, transformada em livro e posteriormente reeditado em 1969. O próprio Moreira Leite informa que essa edição era, na verdade, um novo livro, muito diferente daquele. É a crítica nele expressa que será objeto deste trabalho.

Para Dante Moreira leite, todos os livros que se dedicaram a explicar o Brasil e a buscar a identidade nacional não passam de ideologia ${ }^{82}$. Principalmente porque não foram produzidos na academia. Entretanto, ele mantém um tom cordato e respeitoso para com Sérgio Buarque, seu colega na USP. Bem diferente do tratamento extremamente condenatório que dedica a Casa Grande\&Senzala de Gilberto Freyre. Contudo, ainda bem distante da acolhida que reserva a Evolução Política do Brasil e a Formação do Brasil Contemporâneo de Caio Prado Júnior.

Logo no início do capítulo dedicado ao livro, Cordialidade e aventura, Dante Moreira Leite separa Raizes do Brasil do restante da obra de Sérgio Buarque de Holanda. Reiterando a afirmação de que todos os textos que se propuseram a explicar o Brasil não são obras científicas e sim ideológicas, Moreira Leite considera o livro "fundamentalmente político" - da mesma maneira que Gilberto Freyre tinha um objetivo político - porque discute as formas "de governos e o seu ajustamento à deteminada população" ${ }^{83}$.

Para Moreira Leite não conta o fato de que para aquela geração a questão política era a fundamental. Não conta o fato de que havia grande mobilização na busca de caminhos para o país, da qual participavam os intelectuais. Moreira Leite só atribui valor científico à produção de Caio Prado Júnior, como se este também não fizesse política, esquecendo-se, por exemplo, dos escorregões racistas que se espalham pelas duas obras do estudioso marxista produzida nesse período - Evolução política do Brasil e Formação do Brasil contemporâneo. Escorregões que naquele momento já sofriam contundentes críticas da antropologia.

Entretanto, Moreira Leite não leva em consideração esses 
escorregões. Frisa, isso sim, que Caio Prado Júnior representa um momento decisivo na superação do pensamento ideológico, ao passo que Freyre e Buarque de Holanda faziam apenas política - certamente uma atividade menor, na sua opinião.

Alfredo Bosi é outro intelectual ligado à Universidade de São Paulo que formulou críticas a Sérgio Buarque de Holanda e ressaltou a contribuição de Caio Prado Júnior. Para o professor do Departamento de Letras da FFLCH da USP, Freyre e Buarque de Holanda não deixaram espaço para uma outra visão do Brasil:

A mestiçagem, em Gilberto Freyre, como no velho Sylvio Romero, e a posição excêntrica da Ibéria amarrada ao psiquismo luso, em Sérgio Buarque, acabam respondendo por traços indeléveis de civilização brasileira, e acabam ocupando o lugar que caberia, na visão dos outros (com Caio Prado Jr., por exemplo), aos sistema colonial e ao concurso, que nele se operou, dos regimes escravista e mercantil ${ }^{84}$.

Crítico sempre contundente e preciso, Alfredo Bosi não atribui a Casa grande\&senzala e a Raizes do Brasil nenhuma modernidade. Prefaciando Ideologia da cultura brasileira, de Carlos Guilherme da Motta, seu colega na FFLCH da USP, Bosi ensina:

O trabalho [de Motla] começa com o ajuizamento de alguns grandes estudiosos que se impuseram na década de 30, Gilberto Freyre e Sérgio Buarque de Holanda, aproximáveis pela sua leitura do Brasil. leitura rica e fascinante, servida embora por uma psicologia antiquada. amante de tipologias humorais e contrastes retóricos, tudo embalado complacentemente por uma prosa literária, mais solta no primeiro, mais travada ao gosto antigo no segundo; ambas sinuosamente esquivas à dialética das classes cujos ângulos mais agudos elas encurvam. sob a mole das anotações eruditas e documentos pitorescos. $\dot{E} o$ ensaísmo histórico das causas étnicas, das causas geográficas e das subcausas psicológicas, descontraido então pela experiência norteamericana em Gilberto Freyre e pela prática modernista em Buarque de Holanda. Dai o caráter singularmente misto de ambos, oscilante entre o arcaico e o contemporâneo ${ }^{85}$.

Carlos Guilherme da Mota também destaca a superioridade da obra 
de Caio Prado Júnior em relação às de Sérgio Buarque de Holanda e Gilberto Freyre. Lembra que a crítica dos anos 60 e 70 já apontava o caráter racista de Casa grande \& senzala, "valorização dos traços mestiços da população brasileira" 86 .

Motta é menos virulento em relação a Raízes do Brasil do que em relação a Casa grande\&senzala. Ao contrário de Dante Moreira Leite, que vê na obra de Sérgio Buarque de Holanda uma justificativa para a ditadura $^{87}$, encontra na obra do escritor paulista uma

crítica (talvez demasiado erudita e metafórica) para o incipiente e abafado ambiente cultural e político da época) ao autoritarismo e às perspectivas hierárquicas sempre presentes nas explicações do Brasil ${ }^{88}$.

Como reserva as maiores condenações a Casa grande\&senzala, Motta reconhece em Raizes do Brasil o avanço metodológico, o que já tinha sido acentuado por Antônio Cândido, mas, como Dante Moreira Leite, atribui grande superioridade à Evolução política do Brasil e à Formação do Brasil contemporâneo. Com este último livro, de 1942, Caio Prado Júnior, segundo Carlos Guilherme da Motta,

faz recuar para um terceiro plano obscuro trabalhos como os de Paulo Prado, Retratos do Brasil (1928), Alcântara Machado, Vida e morte do Bandeirante (1928), ou Cassiano Ricardo, Marcha para o Oeste (1943). E para um segundo plano estudos contemporâneos como os de.Fernando Azevedo, A cultura brasileira (1943) e Nelson Werneck Sodré, Panorama do Segundo Império $(1938)^{89}$.

Para Mota, Caio Prado Júnior, embora sem integrar a academia, inaugura a possibilidade da produção "científica", que será concretizado com os primeiros resultados das pesquisas acadêmicas, que começam a aparecer no final dos anos 1940 . É claro que Mota se refere à produção da Universidade de São Paulo.

\section{A permanência de Raizes do Brasil}

O silêncio da crítica no lançamento de Raízes do Brasil vigorou por mais de dez anos. Só em 1948, a José Olympio decidiu lançar uma segunda edição, revista e ampliada por Sérgio Buarque de Holanda. Uma nova edição, mais uma vez revista pelo autor, já então catedrático de 
História da Civilização Brasileira, chegou às livrarias em 1956, no vigésimo aniversário da obra. O curioso é que as edições mexicana e italiana saíram antes. A mexicana integrou a coleção Terra Firme do Fondo de Cultura Econômica e saiu em 1953. A italiana - Alle radici del brasile -, da Fratelli Bocca, de Milão, é de 1954.

Sérgio Buarque de Holanda fez mais uma revisão de Raizes do Brasil para a edição de 1963, a quarta, para a coleção Biblioteca Básica Brasileira da Universidade Nacional de Brasilia. Aparece então o importante prefácio de Antônio Cândido, ao qual se somaria o postscriptum de 1986. Essa tornou-se a edição padrão para as reedições posteriores.

A quinta edição é de 1969, aparecendo a sexta em 1971, a sétima, em 1973, e a oitava em 1975. Daí para a frente, só não saíram novas edições em 1977, 1980, 1985, 1989 e 1994. Em compensação duas edições foram lançadas em 1991. Em 1994, os direitos sobre a obra passaram da José Olympio para a Companhia das Letras, chegando a vigésima sexta edição em 1995. Daí para a frente mereceu seis reimpressões ${ }^{20}$.

Este ano, saiu uma nova edicão francesa, com tradução de Marlyse Meyer para a Gallimard, como parte da Collection Unesco d'Oeuvres Representanives.

É obra referencial, ainda que para certo desgosto de Sérgio Buarque de Holanda. Em entrevista concedida em janeiro de 1976 à revista Veja, ao responder o que o teria levado "a tentar explicar globalmente o caráter nacional brasileiro", o escritor praticamente rejeitava o livro:

Hoje, eu não me aventuraria mais em tentar uma empreitada dessa espécie (...). Eu estava muito influenciado pelo sociólogo alemão $\mathrm{Max}$ Weber (...). O livro está superado e plenamente datado. Minhas preocupações eram outras ${ }^{91}$.

Quando o jornalista lembra que o historiador brasileiro é criticado por ter "a obsessão de ultrapassar rapidamente a realidade empírica e partir para a ensaistica, ou interpretação teórica. sem bases sólidas", Sérgio Buarque de Holanda dá uma lição às novas gerações de historiadores:

Concordo integralmente é é por isso que escreveria de novo 'Raizes 
do Brasil'. Principalmente porque o livro ficou no nivel de ensaio. Não sou contra a ensaistica e a interpretação mesmo hoje. Mas a pesquisa deve ser rigorosa e exaustiva92.

Ao fim da vida ${ }^{93}$, intelectual reconhecido, Sérgio Buarque de Holanda não titubeia a rejeitar certamente a sua obra mais conhecida e indicar o caminho exaustivo, desconfortável e sudorífero da pesquisa para se aproximar da verdade.

Entretanto, o silêncio, a crítica posterior e a rejeição do seu próprio autor não impediram que Raizes do Brasil permanecesse. E que junto de Casa Grande\&Senzala e Evolução Política do Brasil se transformasse em importante instrumento de avaliação de um período nacional, das preocupações dos intelectuais e das diferentes propostas de modernidade para o país. Tornou-se um clássico.

* Este texto é o trabalho final da disciplina História e Modernidade: Olhares sobre a Relação entre o Antigo e o Moderno, ministrada no primeiro semestre de 1998 pelos professores doutores Maria de Lourdes Mônaco Janotti e Antônio Paulo de Morais Rezende, do Programa de Pós-graduação em História da Universidade de São Paulo.

\section{Notas}

' FREYRE, Gilberto. Documentos brasileiros. In: HOLANDA, Sérgio Buarque de. Raizes do Brasil. Rio de Janeiro, Livraria José Olympio Editora, 1936. Documentos Brasileiros, 1, p. III.

${ }^{2}$ CÂNDIDO, Antônio. Post-scriptum. In: Raíes do Brasil. 19. Edição, p. LI. Um comentário escrito em 1986, dez anos depois que o próprio Sérgio Buarque de Holanda rejeitara a obra, como veremos daqui a pouco.

: Sobre a repercussão da obra de Gilberto Freyre, VIANNA, Hermano. O mistério do samba. Rio de Janeiro, Jorge Zahar Editor / Editora da UFRJ, 1995.

${ }^{4}$ Lima Barreto foi outra vítima do silêncio da imprensa. Todas as suas obras, a partir de Memórias do escrivão Isaías Caminha, não receberam qualquer registro em $O$ Correio da Manhã. Isso por que os dirigentes da empresa se viram retratados na obra, que abordava a imprensa do Rio de Janeiro no início do século.

${ }^{5}$ Sérgio Buarque de Holanda continuará exercendo sistematicamen- 
te a critica literária na imprensa diária até 1941, quando deixou de colaborar com o Dicirio de Noticias, do Rio de Janeiro, no qual era responsável por uma famosa coluna de rodapé. Nessa época, ele já era chefe do Setor de Publicações do Instituto Nacional do Livro, cargo que ocupava desde 1937. Era também diretor da Divisão de Consulta da Biblioteca Nacional, de onde se afastaria em 1946, quando retornou a São Paulo.

'LEÃO, Múcio. Registro Literário. In: Jornal do Brasil, 7 de novembro de 1936, p.8. Na mesma seção. na edição de 23 de outubro de 1936, página 6, Múcio Carneiro Leão informa que recebera um exemplar de Raizes do Brasil, o que indica que a editora o enviou aos críticos atuantes da época. O que é perceptivel nas colunas literárias dos outros jornais consultados, que a toda semana registravam novos lançamentos, grande parte deles da José Olympio.

${ }^{7} E$ É bom lembrar aqui de toda uma linhagem de explicadores da América nasce com Domingos Sarmiento e seu livro Facundo.

${ }^{8}$ Sobre isso, MORAES, Eduardo Jardim de. A brasilidade modernista. Rio de Janeiro, Graal, 1978.

"Sérgio Buarque de Holanda nasceu em São Paulo em 11 de junho de 1902. Veio para o Rio em 1921 acompanhando a familia.

${ }^{10}$ Sérgio Buarque de Holanda foi representante da revista Klaxon no Rio de Janeiro, tornando-se seu divulgador entre os intelectuais cariocas.

"O nome da revista. que não era do agrado de Sérgio e de Prudente de Morais Neto, foi uma decisão de Graça Aranha, que se impôs como padrinho da publicação. em uma época em que os modernistas já não tinham por ele o mesmo apreço - ainda que meramente estratégico - de 1922. Sérgio aborda esse periodo em um texto do livro Tentativas de Mirologia. publicado em 1979, pela Perspectiva (Cf. EULÁliO. Alexandre. Sérgio Buarque de Holanda escritor. In: Raizes do Brasil. 19. Edição, p. XXVIII-XXIX).

'2 Afonso Arinos e Prudente de Morais Neto se conheciam desde crianças porque tinham estudado no Colégio Pedro Il. que abrigava a elite na Capital Federal. Arinos fala muito desse período e de sua amizade com Prudente e Sérgio Buarque de Holanda em seu livro de memória $A$ alma do rempo.

1: Sobre o mediador cultural. Levi-Strauss. Claude. A estrutura dos mitos. In: Anrropologia estrutural. Rio de Janeiro. Tempo Brasileiro. 
1975, p.237-265.

${ }^{14} \mathrm{Cf}$. MORSE, Richard. O espelho de Próspero; cultura e idéias nas Américas. São Paulo, Companhia das Letras, 1995. p. 165.

${ }^{15}$ A Tipografia de Francisco de Paula Brito ficava na rua da Constituição, largo do Rocio, hoje praça Tiradentes. Na época, era um espaço na cidade onde conviviam a nobreza e os subalternos. Era cercada de teatros e palacetes de famílias abastadas. Até hoje, esse contraste pode ser percebido na praça, em processo de decadência acentuada, apesar das intervenções públicas dos últimos anos.

${ }^{16}$ Sobre esse encontro, VIANNA, Hermano. O mistério do samba.

${ }^{17} \mathrm{Cf}$. HOLANDA, entrevista a João Marcos Coelho. Revista Veja, 28 de janeiro de 1976, p. 3-6.

${ }^{18}$ LEÃO, Múcio. Registro Literário. In: Jornal do Brasil, 7 de novembro de 1936, p.8.

${ }^{19}$ FREYRE, Gilberto. Documentos brasileiros. In: Raizes do Brasil, primeira edição, p. V.

${ }^{20}$ Múcio Carneiro Leão nasceu em Recife em 1898. Trabalhou no Correio da Manhã, do qual saiu em 1934 para substituir João Ribeiro na crítica literária do Jornal do Brasil. No ano seguinte, foi eleito para a Academia Brasileira de Letras, a qual presidiu em 1944. Com Ribeiro Couto e Cassiano Ricardo, foi um dos fundadores do jornal $A$ Manhã, que revolucionou a imprensa nos anos 40 . Lecionou no curso de Jornalismo da Faculdade de Filosofia da antiga Universidade do Brasil. É autor de vasta bibliografia. Morreu no Rio de Janeiro em 1969.

${ }^{21}$ Idem.

${ }^{22}$ Idem.

${ }^{23}$ A professora Maria de Lourdes Janotti, que foi aluna e amiga de Sérgio Buarque de Holanda, tendo convivido com ele e sua família na casa do Pacaembu, desconhece, por exemplo, que o escritor fosse um "exímio tocador de piano", como afirma Múcio Carneiro Leão. Pode ter ocorrido que, quando a professora Maria de Lourdes Janotti o conheceu, Sérgio Buarque de Holanda tivesse deixado de tocar piano. Mas é possivel supor que o escritor nunca o tenha feito, pois jamais comentou esse fato com ela, que, na época, tocava violão nas rodas em torno do escritor. É bem provável que esse fato seja apenas um mito que cercava um intelectual boêmio freqüentador da Lapa. Mas por que Múcio Carneiro Leão, que conhecia Sérgio, divulgaria esse mito ?

${ }^{24}$ EULÁlIO, Alexandre. Sérgio Buarque de Holanda escritor. In: 
Raíes do Brasil, 19. Edição, p. XXIX.

${ }^{25}$ Para este trabalho foi utilizada a $19^{a}$ edição, de 1987 , da Editora José Olympio.

${ }^{26} \mathrm{CA} N D I D O$, Antônio. O significado de Raizes do Brasil. In: Raizes do Brasil. $19^{a}$ edição, p. XXXIX.

27 Idem, p. XL

${ }^{28}$ Idem, p. XLII.

${ }^{29}$ HOLANDA, p. 3.

30 Idem, p. 5.

"Idem.

32 Idem, p. 9.

${ }^{33}$ Idem.

${ }^{34}$ Idem, p. 7.

${ }^{35} \mathrm{Cf}$. HOLANDA, p. 9.

${ }^{36}$ HOLANDA, p. 11.

${ }^{37} \mathrm{Cf}$. HOLANDA, p. 16.

${ }^{38}$ Idem, p. 33-34.

39 Idem, p. 12-13.

${ }^{40}$ Idem, p. 16.

${ }^{41}$ HOLANDA, p.22

${ }^{42} \mathrm{Cf}$. HOLANDA, p. 23

Setores que, na maioria das vezes, vêem o negro escravo apenas como um animal de carga, incapaz de pensar e de estabelecer estratégias em meio à desgraça da exploração escravista. Isso, entretanto, não é assunto para esse estudo.

${ }^{44}$ HOLANDA, p. 24

${ }^{45}$ Idem, p. 31.

${ }^{46}$ É na década de 1920 que o negro chega à indústria como operário. Isso significou ascensão social. No imaginário das comunidades negras do Rio de Janeiro, um operário de fábrica era pessoa muito importante. Mais até que o compositor e cantor, que também conquistavam espaço profissional naquele momento. Muito mais que o jogador de futebol. Sobre isso, ver MOURA, Roberto. Tia Ciata e a pequena África do Rio de Janeiro. Rio de Janeiro, Funarte, 1983.

${ }^{47} \mathrm{~A}$ idéia de homegeneização é antiga. Vem da tradição cristã-judaica e reúne em torno de si iluministas e marxistas. A raiz do homem é uma só e por isso o "antinatural" é a heterogeneidade. A raiz do racismo está na idéia de heterogeneidade, que pressupõe diferenças essenci- 
ais, algumas insuperáveis.

${ }^{48}$ Sobre isso, ver VIANNA, Hermano. O mistério do samba.

${ }^{49} \mathrm{CÂNDIDO}$, Antônio. O significado de Raizes do Brasil. In: Raizes do Brasil, $19^{a}$ edição, p. XLIX

${ }^{50} \mathrm{Cf}$. HOLANDA, p. 41-42.

${ }^{51}$ HOLANDA, p. 48.

${ }^{52}$ Idem, p. 50.

${ }^{53}$ Idem, p. 51.

${ }^{54}$ Cf. HOLANDA, p. 61-100.

${ }^{55} \mathrm{Cf}$. HOLANDA, nota 157, p. 106-107.

${ }^{56}$ HOLANDA, entrevista a João Marcos Coelho, revista Veja, 28 de janeiro de 1978, p.3-6.

${ }^{57}$ CÂNDIDO, Antônio. O significado de Raízes do Brasil. In: HOLANDA, p. XLVI

${ }^{58}$ HOLANDA, p. 105

${ }^{59}$ CÂNDIDO, Antônio. O significado de Raízes do Brasil. In: HOLANDA, p. XLVI.

${ }^{60}$ HOLANDA, p. 105-106. Um caminho interessante para análise do homem cordial de Sérgio Buarque de Holanda pode ser tomado a partir dos conceitos contemporâneos de simulação - no sentido de fazer parecer aquilo que não é - e dissimulação - ou seja, esconder aquilo que é. Essa possibilidade muito interessante foi levantada, em conversa com autor deste trabalho, pelo antropólogo e historiador Júlio César Tavares - professor da Universidade Federal Fluminénse e doutor pela Universidade do Texas -. É uma boa reflexão, que implica uma série de questões conceituais, incompatível com o espaço deste trabalho.

${ }^{61}$ HOLANDA, p. 127.

${ }^{62}$ Idem, p. 129.

${ }^{63}$ Idem.

${ }^{64}$ Idem, p. 133.

${ }^{65}$ Idem, p. 135.

${ }^{66}$ Idem, p. 141.

${ }^{67}$ Idem.

${ }^{68}$ Idem.

${ }^{69}$ CÂNDIDO, Antônio. O significado de Raízes do Brasil. In: Raizes do Brasil, $19^{\mathrm{a}}$ edição, p. XLVIII.

${ }^{70}$ Idem, XLIX.

${ }^{71}$ Cf. LEÃO, Múcio. Registro literário. In: Jornal do Brasil, 7 de 
novembro de 1936, p. 8

${ }^{72}$ A opção pelos quatro jornais em questão foi circunstancial. Como não era exeqüível consultar todos os periódicos da época, escolhi os de maior prestigio. Não foi possivel ter acesso a $O$ Globo porque a coleção está em processo de microfilmagem na Biblioteca Nacional. Optei por não pesquisar a Folha da Manhã, de São Paulo, por falta de tempo. Foi consultado também o Correio da Manhã, do Rio de Janeiro, no qual não encontrei nenhuma seção sobre livros. A pesquisa nos quatro jornais em tela abrangeu o período de outubro de 1936 a dezembro de 1937.

${ }^{73}$ SODRÉ, Nelson Werneck Sodré. História da imprensa no Brasil. $3^{a}$ edição. São Paulo, Martins Fontes, 1983. p. 190.

${ }^{74}$ Sobre a carreira de Plínio Barreto. SODRÉ. História da Imprensa no Brasil, p. 323, 324, 342, 365, 368, 387, 452.

${ }^{75}$ Sobre o papel de Barreto na rebelião de 1932, HILTON, Stanley. $A$ Guerra Civil Brasileira: história da Revolução Constitucionalista de 1932. $2^{a}$ edição. Rio de Janeiro, Nova Fronteira, 1982.

${ }^{76} \mathrm{O}$ curioso é que Sérgio Buarque de Holanda vivera dois anos na Alemanha por proposta e patrocínio de Assis Chateaubriand, proprietário do $O$ Jornal desde 1929. Como é por demais conhecido o temperamento do empresário, não posso descartar a possibilidade de que o silêncio tenha sido provocado por algum ressentimento pessoal de Chateaubriand. Entretanto, não tenho meios de prová-lo. Acho mesmo uma hipótese improvável.

${ }^{77}$ Nasceu em 1889 no Rio de Janeiro, onde morreu em 1959, na condição de ministro aposentado do Tribunal de Contas da União. A biografia de Bernardo Pereira de Vasconcelos depois integraria aquela que é considerada a principal obra de Otávio Tarquínio de Souza: História dos fundadores do Império, editada em 1954.

${ }^{78}$ Cf. FREYRE, Gilberto. Documentos Brasileiros. In Raizes do Brasil. 1. edição, p. VI.

${ }^{79}$ Formado em Direito no Rio de Janeiro. Sérgio Buarque de Holanda retornou a São Paulo em 1946, convidado para dirigir o Museu Paulista. A partir de 1948 leciona História Econômica do Brasil na Escola de Sociologia e Politica de São Paulo. Sérgio já tivera uma experiência como professor. entre 1936 e 1939, lecionando Cultura LusoBrasileira e História da América na antiga Universidade do Distrito Federal. Ingressou da USP em concurso para catedrático de Civilização Brasileira. sendo aprovado com a erudita tese Visões do paraíso. Lecio- 
nou na Universidade de São Paulo até 1969, quando se aposentou.

${ }^{80} \mathrm{O}$ que pode ser confirmado pela professora Maria de Lourdes Janotti.

${ }^{81}$ LEITE, Dante Moreira. O caráter nacional brasileiro: história de uma ideologia. $2^{\mathrm{a}}$ edição, revista, refundida e ampliada. São Paulo, Pioneira, 1969. 339p.

${ }^{82}$ Entra em cena a discussão, já quase perene, entre ciência e ideologia. Dante Moreira Leite situa-se, sem dúvida, entre os que consideram a ciência imensamente superior à ideologia. Diante da ciência, a política seria uma atividade menor. É uma questão contundente, sem dúvida. Aqui, entretanto, limito-me a apontar a sua existência, já que o limite desse trabalho não permite seu aprofundamento. De qualquer forma, creio ser necessário avisar ao leitor que considero, pessoalmente, a política superior à ciência, em caso de ser necessário estabelecer um peso às duas atividades.

${ }^{83}$ LEITE, p. 286.

${ }^{84} \mathrm{BOSI}$, Alfredo. Um testemunho do presente. In: MOTTA, Carlos Guilherme da. Ideologia da cultura brasileira, p. II.

${ }^{85}$ Idem

${ }^{86}$ MOTA, Carlos Guilherme. Ideologia da cultura brasileira (19331974). $3^{\text {a }}$ edição. São Paulo, Ática, 1977. 303p. Col. Ensaios, 30.

${ }^{87}$ Cf. LEITE, p. 288.

${ }^{88}$ MOTA, p. $30-31$.

${ }^{89} \mathrm{Idem}$, p. 32 . O curioso é que nessa lista de obras que passaram para o segundo e terceiro planos, Mota não inclui Raizes do Brasil e Casa grande\&senzalia.

${ }^{90}$ Segundo a professora Maria de Lourdes Janotti é, sem dúvida, a obra que mais rende direito autoral à viúva de Sérgio Buarque de Holanda, Maria Amélia Buarque de Holanda, que, ainda viva, mora no Rio de Janeiro.

${ }^{91}$ HOLANDA, entrevista a João Marcos Coelho, Revista Veja, 28 de janeiro de 1976, p.3-4.

${ }^{22}$ Idem, p. 6

${ }^{93}$ Sérgio Buarque de Holanda morreu na manhã de 24 abril de 1982 , aos 79 anos. Tinha sete filhos, entre os quais o compositor e escritor Chico Buarque. Em 1969, pedira aposentadoria da USP, em protesto contra o afastamento de colegas com base no Al-5, decretado em dezembro de 1968. Sérgio, que em 1946, após a redemocratização, funda- 
ra a Esquerda Democrática - origem do Partido Socialista Brasileiro filiou-se em 1980 ao Partido dos Trabalhadores, do qual foi um membro-fundador. 
